\title{
Light Emitting Diode Device
}

National Cancer Institute

\section{Source}

National Cancer Institute. Light Emitting Diode Device. NCI Thesaurus. Code C49923.

A type of diode designed to emit light when a current passes through it. 